\title{
Análise Perceptual das Frases Exclamativas e Interrogativas Realizadas por Falantes de Vitória da Conquista/BA
}

\author{
Perceptual Analysis of Exclamative and Interrogative Sentences \\ Speak by Speakers of Vitoria da Conquista/BA
}

\section{Juscelia Silva Novais OLIVEIRA * \\ Vera PACHECO ** Marian OLIVEIRA ***}

\begin{abstract}
Resumo: Este artigo trata de um estudo perceptivo de sentenças exclamativas e interrogativas de falantes conquistenses. O objetivo da pesquisa foi investigar o quanto de variação da $\mathrm{F}_{0}$ é necessária para se garantir a perceptibilidade de um determinado tipo de frase. Os dados foram submetidos a teste de percepção, à ANOVA de Kruskall-Wallis ao e a teste de regressão polinomial quadrática. Para o teste de percepção, alteramos de três maneiras distintas a $\mathrm{F}_{0}$ do componente tônico, aquele que possui a sílaba tônica saliente do enunciado. Os dados foram manipulados por meio do software PRAAT, onde a $\mathrm{F}_{0}$ foi modificada de forma a obter valores ascendentes e descendentes de 25, 50 e 75 em relação ao valor médio do sinal original no componente tônico. Os resultados evidenciaram que a $\mathrm{F}_{0}$ tem um papel relevante no desenvolvimento da percepção dos contornos melódicos. Considerando os princípios básicos da Teoria Quântica (STEVENS, 1972, 1989), podemos
\end{abstract}

\footnotetext{
* Mestrado em Linguística (2014) pela Universidade Estadual do Sudoeste da Bahia. Contato: juscelyaoliveira@gmail.com.

** Doutorado Linguística (2006) pela Universidade Estadual de Campinas. Professora Doutora da Universidade Estadual do Sudoeste da Bahia. Contato: vera.pacheco@gmail.com.

*** Doutorado em Linguística (2011) pela Universidade Estadual de Campinas. Professora Doutora da Universidade Estadual do Sudoeste da Bahia. Contato: mdossoliveira@gmail.com.
} 
dizer que faixas de frequências específicas favorecem a percepção dos tipos entoacionais, constituindo, assim, regiões quânticas que definem padrões melódicos os quais contrastam exclamativas e interrogativas. Quando o sinal acústico não apresenta região quântica específica para o contraste de exclamativa e interrogativa, o processo de percepção desses tipos de orações é comprometido.

Palavras-chave: Exclamativa. Interrogativa. Percepção.

Abstract: This paper is a perceptive study of interrogative and exclamative sentences of speakers from Vitoria da Conquista, Bahia. The aim of the research was to investigate just how much of variation of the $\mathrm{F}_{0}$ is needed to ensure the perceptibility of a particular type of sentence. The analyses were performed in sentences with and without pronoun, since we also aimed to know to what extent the syntactic structure favors or not the melodic perception. The data were subjected to perception test, Kruskall-Wallis ANOVA and quadratic polynomial regression. For the perception test, we changed in three distinct ways the $\mathrm{F}_{0}$ of the tonic component, one that has the salient stressed syllable of the utterance. Data were handled through the software PRAAT in which the $\mathrm{F}_{0}$ was modified to obtain ascending and descending values of 25,50 and 75 compared to the average value of the original signal in the tonic component. The results showed that the $\mathrm{F}_{0}$ plays an important role in developing the perception of the melodic contours. Considering the basic principles of the Quantum Theory (Stevens 1972, 1989), we can say that specific frequency bands favor the perception of the intonation types, thus constituting quantum regions responsible for defining the melodic patterns which contrast interrogative and exclamative sentences. When the acoustic signal does not present specific quantum region for the contrast among interrogative and exclamative sentences, the process of perception of these types of sentences is compromised.

Keywords: Exclamative. Interrogative. Perception.

\section{Introdução}

Estudos realizados na área da prosódia têm mostrado a grande importância da entoação no processo comunicativo. A entoação funciona como uma estratégia do falante para transmitir significados necessários para construção do sentido. 
A entoação refere-se à altura de $\mathrm{F}_{0}$ e ao contorno melódico de uma frase e indica a modalidade a qual ela pertence, se é interrogativa, exclamativa, afirmativa, ou outra. É possível, somente a partir do contorno entoacional, usar as mesmas palavras e produzir uma frase interrogativa ou uma afirmativa. Isso só ocorre devido às variações da frequência da onda sonora propagada quando falamos, sendo percebidas como variações da altura do som. Assim, quando falamos, variamos a altura da voz, que ora apresenta movimento ascendente, ora apresenta movimento descendente, criando, assim, um contorno melódico.

As variações melódicas são resultado das vibrações nas pregas vocais que ocasionam uma onda acústica regular na corrente de ar da produção da voz. Em termos acústicos e perceptuais, as vibrações nas pregas vocais têm, como correlato acústico, a frequência fundamental $\left(\mathrm{F}_{0}\right)$, harmônico de menor frequência, e como correlato perceptual, a altura (SCARPA, 1999). No geral, o estudo entoacional está relacionado à variação da $\mathrm{F}_{0}(\mathrm{FRY}, 1976)$. Para Moraes (2003), a entonação se refere às modulações melódicas que ocorrem no nível da frase (MORAES, 1998).

Partindo de uma abordagem perceptual, a fim de avaliar a percepção do pitch da fala, 't Hart, Collier e Cohen (1990) compreendem a entonação como sendo, essencialmente, variações da $F_{0}$.

A variação de altura, que gera o contorno melódico, é importante para que um interlocutor consiga perceber qual é a intenção que há em uma frase quando pronunciada. A variação da $\mathrm{F}_{0}$ no sentido ascendente, por exemplo, assinala uma interrogação ou expressa uma incerteza. Quando a variação da $\mathrm{F}_{0}$ está no sentido descendente, tem-se um enunciado afirmativo, um exclamativo ou um imperativo e exprime-se uma certeza, uma conclusão ou uma ordem (MATEUS et al., 1994). A F f $_{0}$ juntamente com a intensidade e a duração (LEHISTE, 1970), assume, portanto, um papel importante na percepção da melodia de uma frase, na medida em que seus valores interferem na mudança da curva melódica, o que é determinante para o significado.

Sabendo que a $\mathrm{F}_{0}$ é um coadjuvante importante na percepção das variações melódicas, a questão que trazemos para este estudo é: o quanto de variação da $\mathrm{F}_{0}$ é necessário para se garantir a perceptibilidade de um determinado tipo de frase? No intuito de compreender o processo de percepção de frases exclamativas e interrogativas, o objetivo deste trabalho é determinar o papel da $\mathrm{F}_{0}$ no processo de percepção de uma exclamação e de uma pergunta. Ou seja, o trabalho pretende compreender o impacto da $\mathrm{F}_{0}$ 
no processo de percepção de frases exclamativas e interrogativas com e sem pronome, observando até que ponto a manipulação da $\mathrm{F}_{0}$ interfere na percepção da melodia da frase.

A pesquisa buscou explicações possíveis para os resultados encontrados nos fundamentos da Teoria Quântica da Percepção da Fala idealizada por Stevens $(1972,1989)$ que prioriza a audição no processo de percepção.

O corpus deste estudo foi composto por sentenças exclamativas com e sem pronome e por sentenças interrogativas parciais (com pronome) e totais (sem pronome), a fim de saber se a $\mathrm{F}_{0}$ apresenta a mesma relevância para $\mathrm{O}$ processo perceptivo nas diferentes estruturas sintáticas. A hipótese que levantamos é a de que a $\mathrm{F}_{0}$ possui um impacto menor para a percepção dos enunciados com a presença de um pronome inicial. Para esses casos, essa marca morfológica seria uma grande aliada do ouvinte no reconhecimento da modalidade da frase. Entretanto, nos enunciados sem pronome, ocorre o contrário, ou seja, o impacto da $\mathrm{F}_{0}$ seria maior devido à ausência do pronome inicial.

\section{O Padrão Melódico de Frases Exclamativas e Interrogativas de Falantes Conquistense}

Os contornos entoacionais determinam a modalidade dos enunciados. Dessa forma, cada enunciado se caracteriza por apresentar particularidade em seu contorno melódico. As oposições que há entre os tipos de frases encontram-se em pontos precisos do enunciado, pontos que são determinados pela posição da sílaba tônica saliente.

Oliveira (2014), tomando como base o modelo entoacional de Halliday (1970) e Cagliari (1982, 2007), descreve o padrão entoacional de frases exclamativas e interrogativas do dialeto de Vitória da Conquista, na Bahia. De acordo com esse modelo, uma sentença é constituída por unidade entoacional denominada de grupo tonal (GT). O GT é a unidade básica para a descrição da entoação e carrega um conteúdo semântico, isto é, "representa uma 'unidade de informação' que o falante quer transmitir" (CAGLIARI, 2007, p. 163). Em um GT, há sempre uma sílaba tônica saliente (STS), essa, por sua vez, traz a marca entoacional mais importante, isto é, a maior variação do contorno melódico. Essa variação é denominada de tom. A partir da sílaba tônica saliente, um GT é dividido em um componente pretônico (CPT), o elemento dado, e um componente tônico (CT), o elemento novo. O início do CT é marcado a partir da STS (CAGLIARI, 2007). 
A descrição foi feita a partir da mensuração da $F_{0}$ em três pontos (início, meio e fim) de todas as sílabas tônicas das sentenças exclamativas e interrogativas, tanto do componente tônico quanto do componente pretônico. Com esse procedimento foi possível avaliar a curva de $\mathrm{F}_{0}$ das sílabas tônicas, verificar o movimento da $\mathrm{F}_{0}$ nos componentes pretônico e tônico e, assim, descrever a tendência dos padrões melódicos das frases exclamativas e interrogativas de falantes do dialeto conquistense.

Oliveira (2014) verificou que: a) o contorno final dos enunciados exclamativos e interrogativos de falantes conquistenses se assemelha ao padrão descrito por Moraes (2008) para o PB; b) a mudança significativa ocorre na sílaba tônica saliente do enunciado, como acontece na variante carioca; d) os resultados encontrados permitem caracterizar o padrão exclamativo e interrogativo de falantes conquistenses: exclamativa, com e sem pronome, com contorno melódico descendente no final do enunciado e interrogativa total com contorno ascendente e interrogativa parcial, descendente.

Assumindo esses contornos entoacionais encontrados no dialeto de Vitória da Conquista como padrão-base para nossa pesquisa, realizamos um teste de percepção elaborado a partir dos dados de fala original e manipulada com o objetivo de verificar os índices de acerto e de recuperabilidade da modalidade da frase pelos informantes; e um teste de regressão polinomial quadrática feito com o objetivo de investigar a dependência ou não entre os índices de acerto e recuperabilidade e a $\mathrm{F}_{0}$.

\section{Algumas Considerações sobre Percepção da Fala: a Teoria Quântica da percepção da fala}

Dada à complexidade que é o processo de percepção da fala, diferentes teorias buscam explicar os processos envolvidos durante a percepção da fala. Essas teorias têm sido motivadas por questionamentos essenciais, a saber: a) como o ouvinte consegue extrair informações precisas para a compreensão da fala? b) de que forma os ouvintes reconhecem os sons da fala a partir de uma série contínua de sons, tendo uma taxa de transmissão que quase sempre ultrapassa a capacidade de resolução do mecanismo auditivo? c) o sinal da fala é processado pelos ouvintes por uma base, preponderantemente, auditiva?, ou é extraído através de informação fonética essencial para a produção do som? ou; d) ambos os procedimentos são realizados pelos ouvintes? (BORDEN et al., 1994). 
Dentre as diferentes perspectivas teóricas, destacamos a Teoria Quântica da Percep̧cão da Fala, defendida por Stevens (1972, 1989), que sugere que a percepção da fala tem por base o sinal acústico, independente da forma como o som é produzido, a percepção se dá pela audição (PACHECO, 2006).

De acordo com Stevens (1972, 1989), não é proporcional o número de articulações diferentes produzidas no trato vocal ao número de sons que compõe o sistema fonológico de uma língua, devido ao fato de não ser linear a relação entre os parâmetros articulatórios e o output acústico. Em alguns casos os parâmetros acústicos podem ser relativamente insensíveis a uma mudança grande no parâmetro articulatório, ou seja, variações na articulação não causam necessariamente efeito no output da fala (PACHECO, 2006)

A falta de linearidade entre os movimentos articulatórios e o sinal acústico é explicada pela Teoria Quântica a partir do fato de diferentes variações do parâmetro articulatório configurarem platôs ou saltos nos parâmetros acústicos (JOHNSON, 1997 apud PACHECO, 2006). Dessa forma, pequenas mudanças nos parâmetros articulatórios poderiam resultar em grandes mudanças no parâmetro acústico, e grandes variações nos parâmetros articulatórios poderiam provocar variações irrelevantes nos parâmetros acústicos.

A proposta teórica é que regiões de platôs do sinal acústico sejam correlatos de traços distintivos. Dessa forma, os contrastes linguísticos envolvem diferenças entre as regiões quânticas. Todas as regiões quânticas definem sons contrastivos e todos os sons contrastivos diferem quanticamente. (PACHECO, 2006, p. 23).

A Teoria Quântica, portanto, fundamenta-se nas regiões quânticas do sinal acústico, percebidas a partir da audição, enquanto a Teoria Motora prioriza os movimentos articulatórios, percebidos a partir da visão. Estudos realizados, entretanto, como o artigo Visual Contribuition to Speech Intelligibility in Noise, de W. H Sumby e I. Pollack (1954) e os trabalhos de Liberman et al. (1967) assinalaram para o fato de a percepção da fala ser de natureza bimodal, isto é, durante o processo de percepção da fala, a visão e a audição são acionadas (PACHECO, 2006). 
Os resultados do estudo realizado por Pacheco (2006) sobre o efeito dos estímulos auditivo e visual na percepção dos marcadores prosódicos lexicais e gráficos usados na escrita atestam que a percepção dos marcadores prosódicos lexicais tem base predominantemente auditiva, não apresentando influência significativa da visão; enquanto os marcadores prosódicos gráficos, com pistas visuais mais proeminentes, são percebidos a partir da integração dos estímulos, visão e audição. Para Pacheco (2006), o processo de percepção dos marcadores prosódicos traz evidências tanto para a Teoria Quântica da Percepção da Fala, quanto para as teorias que defendem a participação da visão na percepção da fala, como a Teoria Motora da Percepção da Fala.

Focando o objetivo central desta pesquisa, realizar uma análise do papel da $\mathrm{F}_{0}$ na percepção de enunciados exclamativos e interrogativos totais e parciais do português do Brasil na variedade de Vitória da Conquista, e com base no achado de Pacheco (2006), no que se refere à percepção dos marcadores prosódicos lexicais e em função do delineamento experimental utilizado, supomos que, nesse momento da pesquisa, os princípios gerais da Teoria Quântica da Percepção da Fala podem lançar luz à interpretação e compreensão dos resultados aqui obtidos.

\section{Material e Método}

Para alcançar os objetivos propostos, realizamos as etapas metodológicas expostas a seguir.

\subsection{Coleta de dados}

O corpus deste estudo foi composto por gravações de sentenças exclamativas e interrogativas. As sentenças foram gravadas no Laboratório de Pesquisa em Fonética e Fonologia (LAPEFF), da Universidade Estadual do Sudoeste da Bahia (UESB). Contamos com a colaboração de seis sujeitos, três do sexo feminino e três do sexo masculino, naturais de Vitória da Conquista.

\subsection{Manipulação do sinal acústico}

Com o intuito de quantificar a ação da $\mathrm{F}_{0}$ na identificação e discriminação dos padrões entoacionais de frases exclamativas e interrogativas, realizamos 
manipulação da $\mathrm{F}_{0}$ em diferentes taxas. Para isso, escolhemos uma frase de cada modalidade pesquisada que estava mais prototipicamente marcada da interrogativa total, interrogativa parcial com o pronome por que, exclamativa com pronome como e exclamativa sem pronome ${ }^{1}$. A manipulação dos contornos melódicos foi feita a partir de um recurso do programa Praat (to manipulation) (BOERSMA; WEENINK, 2006).

Como já foi elucidado, é na sílaba tônica saliente que ocorre a mudança da altura melódica de acordo com Halliday (1970) e Cagliari (1982, 2007). A indicação da modalidade de uma frase é feita na sílaba tônica saliente do enunciado que, por sua vez, recai no final do enunciado. Sendo assim, nos nossos dados, decidimos alterar de três maneiras distintas a $\mathrm{F}_{0}$ desse componente tônico.

A manipulação se deu a partir do balanceamento da $\mathrm{F}_{0}$, obtido através do pitch médio desse componente tônico, resultado da soma do valor mínimo da $\mathrm{F}_{0}$ mais o valor máximo dividido por dois. A partir desse valor médio da $\mathrm{F}_{0}$, foram aplicadas três taxas de manipulação, $25,50,75$, tanto ascendente quanto descendente. Todos os valores da $\mathrm{F}_{0}$ foram dados em $\mathrm{Hz}$.

\subsection{Testes de percepção}

Para montar o teste de percepção, os quatros enunciados originais e os 24 oriundos da manipulação da $\mathrm{F}_{0}$ foram inseridos em arquivos de áudio e ouvidos por seis informantes. Foram desenvolvidas duas tarefas: a tarefa de identificação e a tarefa de discriminação. As tarefas foram aplicadas, uma após a outra, aos informantes individualmente. Os testes foram aplicados por meio do software Transcriber (Versão 2.0.0), ferramenta usada para transcrição e anotação de sinais de voz. Os arquivos de áudio foram colocados no formato WAV.

\footnotetext{
${ }^{1}$ Embora tenhamos analisado a realização de sentenças produzidas com outros pronomes, escolhemos trabalhar somente com dois pronomes, um para a exclamativa e outro para a interrogativa, para evitar quantidade excessiva de dados para a tarefa de percepção. Futuramente será avaliado se o tipo de pronome interfere no processo de percepção.
} 


\subsubsection{Tarefa de identificação}

A tarefa de identificação teve como objetivo avaliar a identificação pelo informante da modalidade da frase que estava sendo ouvida. Para tanto, foram montados 04 arquivos de áudio com 28 estímulos sonoros. Os arquivos foram montados com os enunciados originais de cada tipo trabalhado e os enunciados manipulados a três taxas $(25,50$ e 75$)$ para mais e para menos, o que resultou em arquivo com 28 estímulos sonoros. Assim foram criados quatro arquivos de áudio com os mesmos enunciados, originais e manipulados, mas com sequências distintas, definidas por meio de sorteio. Para a realização da tarefa, o informante ficava sozinho em uma sala com o computador, o que garantia sua maior concentração. Os arquivos foram apresentados um por vez, o informante ouvia uma frase e tinha que responder de imediato, pressionando a tecla " $\mathrm{x}$ " do computador, se a oração ouvida por ele era uma exclamativa, uma interrogativa ou outra coisa. O informante, ao apertar a tecla TAB do computador, ouvia cada arquivo de áudio somente uma vez. Dessa forma os intervalos entre os estímulos eram determinados pelos informantes. Com esse procedimento obtivemos a variável índice de acerto.

\subsubsection{Teste de discriminação}

O teste de discriminação teve por objetivo saber se uma sentença interrogativa ou exclamativa é recuperada como tal quando tem a $\mathrm{F}_{0}$ do componente tônico alterada para mais ou para menos. O informante teve de discriminar se dois estímulos sonoros, um original e outro com a frequência manipulada, eram iguais ou diferentes entre si quanto à entonação. Para a realização da tarefa, foram montados quatro arquivos de áudios com 28 enunciados: os quatros originais e os mesmos manipulados a taxas de 25, 50 e 75 para mais e para menos. Os enunciados foram apresentados em pares. Cada estímulo continha 24 pares de enunciado. A ordem como os pares foram dispostos no arquivo foi escolhida por sorteio. Os pares eram formados por um enunciado original e um manipulado, tanto para mais como para menos. Tivemos, assim, por exemplo, interrogativa parcial original + interrogativa parcial manipulada a +25 ; interrogativa parcial original + interrogativa parcial manipulada a +50 , etc.. Dessa forma, o informante tinha de ouvir 24 pares de oração e responder, a cada par apresentado, se as duas orações ouvidas eram iguais ou diferentes quanto à melodia. Cada arquivo 
de áudio era ouvido uma vez pelo informante. A resposta também era dada pressionando a tecla " $\mathrm{x}$ " do computador. $\mathrm{O}$ informante ficava sozinho em uma sala com o computador, o que garantia sua maior concentração. A variável obtida com a tarefa de discriminação foi o índice de recuperabilidade.

\subsection{Tabulação dos dados}

Depois de todos os testes prontos, as respostas dadas foram tabuladas em uma planilha Microsoft Office Excel 2007. Na tarefa de identificação, a resposta dada era classificada em certo, errado e outra. Quando o informante escolhia a resposta que de fato correspondia à modalidade ouvida, a resposta era classificada como certa. Era classificada como errada quando a resposta dada não era a modalidade ouvida. E, se a resposta dada não era nenhuma das modalidades dadas, a resposta era enquadrada em outra. Já para a tarefa de discriminação, as respostas foram distribuídas em iguais e diferentes.

Feita a tabulação dos dados, foi tirada a porcentagem de resposta por informante.

\subsection{Análises estatísticas}

Com os valores obtidos na etapa anterior, foi possível realizar as análises estatísticas por meio do software Bio Estat (AYRES et al., 2003). Foram escolhidos dois testes. O primeiro, o Anova de Kruskal-Wallis, teste indicado para fazer a comparação de três ou mais amostras independentes, do mesmo tamanho amostral ou de tamanhos desiguais (AYRES et al., 2003, p. 75).

O segundo teste empregado foi o teste de regressão polinomial quadrática que serviu para verificar a dependência entre as variáveis avaliadas. Esse teste tem por finalidade determinar a dependência de uma variável em relação à chamada variável independente ou preditora (AYRES et al., 2007, p.215). A depender da natureza da variável independente, há vários tipos de teste de regressão que podem ser usados.

O teste de regressão polinomial é indicado nos casos em que a variável independente apresenta intervalos iguais. A nossa variável independente ou preditora é a $\mathrm{F}_{0}$ que se apresenta em intervalos regulares, pois a partir da $\mathrm{F}_{0}$ original foram gerados os demais valores que são 25, 50 e 75 daquela.

As variáveis dependentes são o índice de acerto e o índice de recuperabilidade, que podem variar em função dos valores da $\mathrm{F}_{0}$, nossa variável independente. 
Além do valor de $p$, na regressão, precisamos avaliar também o valor do $\mathrm{R}^{2}$, que é o coeficiente de determinação, valor que determina o quanto a variável dependente é explicada pela variável preditora (independente). O R ${ }^{2}$ pode variar de 0 a 1 e quanto mais próximo de 1 , mais a variável dependente é explicada pela variável independente.

Precisamos analisar o valor de $\mathrm{R}^{2}$, quando o valor de $p$ for significativo (menor ou igual a 0,05$)$.

\subsection{Informantes}

Participaram dos testes de percepção seis informantes nativos do português brasileiro, variedade de Vitória da Conquista, três do sexo feminino e três do sexo masculino, com idades compreendidas entre 24 e 36 anos, sem problemas de audição. Todos os informantes residem em Vitória da Conquista e, com exceção de um, todos possuem formação de nível superior. Esses sujeitos tinham por função servir de julgadores nas tarefas de percepção

\section{Resultados e discussão}

\subsection{Análise perceptual das exclamativas: tarefa de identificação}

Para darmos conta da análise perceptual dos resultados obtidos nas tarefas de identificação, passamos a avaliar os índices médios de acerto.

São apresentados na Tabela 1 os resultados obtidos na tarefa de identificação das exclamativas com e sem pronome. 
Tabela 1 - Índices médios de acerto obtidos na tarefa de identificação das exclamativas com $\mathrm{F}_{0}$ da sílaba tônica do CT original, ampliada e reduzida a 25, 50 e 75

\begin{tabular}{|c|c|c|c|c|c|c|c|c|c|c|}
\hline \multirow[b]{3}{*}{$\begin{array}{l}\text { Tipos de } \\
\text { sentença }\end{array}$} & \multicolumn{9}{|c|}{ Condições experimentais } & \multirow{3}{*}{$\mathrm{p}$} \\
\hline & \multicolumn{4}{|c|}{$\begin{array}{c}\text { Taxas de ampliação da } \mathrm{F}_{0} \\
\text { da sílaba tônica do CT } \\
(\%)\end{array}$} & \multirow[t]{2}{*}{$\mathrm{p}$} & \multicolumn{4}{|c|}{$\begin{array}{c}\text { Taxas de redução da } \mathrm{F}_{0} \mathrm{da} \\
\text { sílaba tônica do CT } \\
(\%)\end{array}$} & \\
\hline & Original & +25 & +50 & +75 & & Original & -25 & -50 & -75 & \\
\hline $\begin{array}{c}\text { Exclamativa } \\
\text { com } \\
\text { pronome }\end{array}$ & 91,7 & 95 & 87,5 & 95,8 & $0,5467 \mathrm{~ns}^{(1)}$ & 91,7 & 100 & 87,5 & 91,7 & $0,3235 n s$ \\
\hline $\begin{array}{l}\text { Exclamativa } \\
\text { sem } \\
\text { pronome }\end{array}$ & 79,17 & 87,5 & 75 & 79,17 & $0,6463 \mathrm{~ns}$ & 79,17 & 70,8 & 58,3 & 54,17 & $0,1604 \mathrm{~ns}$ \\
\hline
\end{tabular}

Fonte: As autoras.

Obs: ${ }^{(1)} \mathrm{ns}=$ não significativo para $\mathrm{p}>0,05(\mathrm{alfa}=0,05)$.

\section{Exclamativa com pronome ampliada e reduzida}

De acordo com os valores apresentados na Tabela 1, a exclamativa com pronome foi bem reconhecida pelos informantes, atingido valores acima de $90 \%$ quando ampliada a 25 e 75 . A diferença entre os índices médios de acerto nas diversas condições experimentais não foi significativa ( $\mathrm{p}=$ 0,5467 ns). Observamos com esses valores, que a ampliação da $\mathrm{F}_{0}$ compromete em baixas porcentagens a percepção desse tipo de frase. $\mathrm{O}$ maior comprometimento de identificação é observado para a manipulação da $\mathrm{F}_{0}$ a 50 , que foi de $12.5 \%$, já que nessa condição experimental, obtivemos $87.5 \%$ de acerto.

Considerando o padrão entoacional de uma exclamativa, qual seja, contorno descendente no acento nuclear, a alta performance de identificação desse tipo de sentença, com ampliação da $F_{0}$, por parte dos informantes chama a atenção. Nessa condição experimental, o esperado era que houvesse dificuldade para o reconhecimento da modalidade frasal, já que a $\mathrm{F}_{0}$ foi manipulada em sentido oposto ao movimento da frequência fundamental no componente tônico.

Diante desse resultado, nossa hipótese é a de que a percepção dessa exclamativa seja de fato desencadeada pela presença do pronome. E, nesse sentido, portanto, a identificação dessa oração é mais morfológica que entoacional. 
Já o índice de acerto das exclamativas com pronome quando reduzidas a 25, 50 e 75 também foi considerado alto. Em todas as condições experimentais, o índice de acerto foi superior a $80 \%$, chegando a $100 \%$ quando manipulada a 25. A partir desses resultados, é possível afirmar que a manipulação da $\mathrm{F}_{0}$ também não prejudicou a percepção da frase.

A diferença entre os índices médios de acerto nas diversas condições experimentais não foi significativa ( $\mathrm{p}=0,3235 \mathrm{~ns})$.

Sendo o padrão entoacional das exclamativas descendente, esperavase que as orações exclamativas com a frequência reduzida obtivessem uma média maior de acerto em relação às exclamativas que tiveram sua $\mathrm{F}_{0}$ ampliada. Com exceção do desempenho obtido na oração modificada a 25 , que foi maior quando reduzida, o desempenho dos informantes nas demais condições experimentais não foi o esperado, quando a $\mathrm{F}_{0}$ foi reduzida a 50 , a porcentagem de acerto foi 87.5, valor igual ao obtido com a $F_{0}$ ampliada a 50, e a 75 , o índice de acerto foi de 91.7, ou seja, menor do que quando a $F_{0}$ foi ampliada a 75 .

Ao comparar os resultados da $\mathrm{F}_{0}$ ampliada com os da $\mathrm{F}_{0}$ reduzida, temos mais uma evidência de que é o pronome o grande responsável pela do tipo entoacional exclamativo.

\section{Exclamativas sem pronome ampliada e reduzida}

Os índices de acerto para as exclamativas sem pronome foram menores quando comparados com os das exclamativas com pronome nas mesmas condições experimentais. Mesmo assim, consideramos que houve facilidade dos informantes em identificar a entonação da frase, visto que a média de acerto foi superior a $70 \%$ quando a $\mathrm{F}_{0}$ foi ampliada em todas as taxas de manipulação, conforme mostra a Tabela 1. A diferença entre os índices médios de acerto, com $\mathrm{F}_{0}$ ampliada nas diversas condições experimentais não foi significativa ( $\mathrm{p}=0,6463 \mathrm{~ns})$.

Os valores para as exclamativas sem pronome ampliadas não foram os esperados, levando-se em conta que a curva melódica das exclamativas tem contorno descendente. Como não esperávamos também que uma oração manipulada alcançasse valor de reconhecimento mais elevado que a oração original, como ocorreu com a oração ampliada a 25.

O menor índice de acerto obtido para as exclamativas sem pronome com a $\mathrm{F}_{0}$ ampliada a 75 evidencia que a ausência do pronome torna um 
pouco mais difícil a identificação desse tipo de frase. O maior índice de acerto da exclamativa sem pronome gira em torno do menor índice de acerto da exclamativa com pronome, aproximadamente $87.5 \%$.

Conforme apresentado na Tabela 1 , os valores de reconhecimento da exclamativa sem pronome com a frequência reduzida foram menores que quando ampliada, apesar de as condições experimentais serem mais favoráveis à percepção de uma exclamativa considerando seu contorno entoacional. $\mathrm{O}$ índice de acerto diminui conforme o aumento da taxa de manipulação, ou seja, foi de $70,8 \%$ quando a $F_{0}$ foi reduzida a 25 , de 58,3 , a 50 e de $54.17 \%$ quando reduzida a 75 . Essa queda no desempenho dos informantes é claramente entendida e aceita. Aqui, a diferença entre os índices médios de acerto nas diversas condições experimentais, com $\mathrm{F}_{0}$ reduzida, não foi significativa ( $\mathrm{p}=0,6463 \mathrm{~ns})$.

Para exclamativas sem pronome, a redução da $\mathrm{F}_{0}$ acarreta uma perda de identificação maior do que para os outros tipos entoacionais, chegando ao comprometimento de $45.83 \%$ quando a fundamental está reduzida a 75 .

Para as exclamativas sem pronome, a modulação da $\mathrm{F}_{0}$ dentro dos parâmetros ideais concorre positivamente para uma melhor performance no processo de identificação de uma exclamativa.

\subsection{Análise perceptual das exclamativas: tarefa de discriminação}

O objetivo dessa tarefa era saber se uma sentença interrogativa ou exclamativa, uma original e outra com a frequência manipulada, é recuperada como tal quando tem a $\mathrm{F}_{0}$ do componente tônico alterada para mais ou para menos. O ouvinte teve de discriminar se dois estímulos sonoros eram iguais ou diferentes entre si quanto à entonação. Essa análise contou com a observação dos índices médios de recuperabilidade obtidos nas tarefas de discriminação.

A seguir na Tabela 2 são apresentados os índices médios de recuperabildade, obtidos na tarefa de discriminação das exclamativas com e sem pronomes. 
Tabela 2 - Índices médios de recuperabilidade obtidos na tarefa de discriminação das exclamativas com $\mathrm{F}_{0}$ da sílaba tônica do CT ampliada e reduzida a 25,50 e 75

\section{Condições experimentais}

\begin{tabular}{|c|c|c|c|c|c|c|c|c|}
\hline \multirow[t]{2}{*}{$\begin{array}{l}\text { Tipos de } \\
\text { sentença }\end{array}$} & \multicolumn{3}{|c|}{$\begin{array}{c}\text { Taxas de } \\
\text { ampliação da } \mathrm{F}_{0} \\
\text { da sílaba tônica } \\
\text { do CT } \\
(\%)\end{array}$} & \multirow[t]{2}{*}{$\mathrm{p}$} & \multicolumn{3}{|c|}{$\begin{array}{c}\text { Taxas de redução } \\
\text { da } F_{0} \text { da sílaba } \\
\text { tônica do CT } \\
(\%)\end{array}$} & \multirow[t]{2}{*}{$\mathrm{p}$} \\
\hline & +25 & +50 & +75 & & -25 & -50 & -75 & \\
\hline $\begin{array}{c}\text { Exclamativa } \\
\text { com } \\
\text { pronome }\end{array}$ & 70,8 & 12,5 & 0 & $0,0046 \mathrm{~s}^{(1)}$ & 25 & 37,5 & 54,17 & $0,3141 \mathrm{~ns}^{(2)}$ \\
\hline $\begin{array}{l}\text { Exclamativa } \\
\text { sem } \\
\text { pronome }\end{array}$ & 62,5 & 12,5 & 0 & $0,0351 \mathrm{~s}$ & 70,8 & 45,8 & 41,66 & $0,3539 \mathrm{~ns}$ \\
\hline
\end{tabular}

Fonte: As autoras.

OBS: ${ }^{(1)} \mathrm{s}=$ significativo para p d" $0,05(\mathrm{alfa}=0,05)$.

(2) $\mathrm{ns}=$ não significativo para $\mathrm{p}>0,05(\mathrm{alfa}=0,05)$.

\section{Exclamativa com pronome ampliada e reduzida}

Os índices de recuperabilidade encontrados para os pares de estímulos formados por uma oração original mais uma oração com $\mathrm{F}_{0}$ ampliada foram menores conforme o aumento de taxa de manipulação. Ou seja, quanto maior foi a taxa de manipulação, menor foi a percepção das frases como sendo da mesma modalidade. Os valores da Tabela 02 mostram que o par de estímulos que teve maior índice de recuperabilidade foi o que apresentava a oração manipulada a 25 , com um índice de recuperabilidade de $70,8 \%$. Nenhum informante recuperou a manipulada a 75 como sendo igual às frases ouvidas, obtendo $0 \%$ de perceptibilidade. A manipulada a 50 teve $12.5 \%$ de recuperação das orações como sendo iguais.

A diferença entre os índices médios de recuperabilidade do padrão melódico da sentença nas diversas condições experimentais foi significativa $(\mathrm{p}=0,0046 \mathrm{~s})$. 
Os pares de estímulos com a oração original mais oração com a $\mathrm{F}_{0}$ reduzida renderam resultados curiosos. $\mathrm{O}$ par de estímulos que teve o maior índice de recuperabilidade foi o que apresentava a oração reduzida a 75 , a recuperabilidade foi de $54.17 \%$, quando o esperado era que os informantes respondessem como sendo estímulos diferentes já que a oração modificada a 75 apresentava uma estranha entonação. E o par de estímulos com menor índice de reconhecimento foi o que apresentava a oração reduzida a 25, o que também chama atenção devido ao fato de a mudança na curva melódica ser quase imperceptível. $\mathrm{Na}$ exclamativa reduzida a 50 , houve $37.5 \%$ de reconhecimento.

A diferença entre os índices médios de recuperabilidade do padrão melódico da sentença nas diversas condições experimentais não foi significativa ( $\mathrm{p}=0,3141 \mathrm{~ns})$.

\section{Exclamativas sem pronome ampliada e reduzida}

A ampliação da $\mathrm{F}_{0}$ das exclamativas sem pronome, nas condições experimentais de 50 e 75, provocou confusão aos informantes (cf. Tabela 2). $\mathrm{O}$ índice de recuperabilidade foi de apenas 12,5 com frequência ampliada a 50 e de 0 quando ampliada 75, ainda de acordo com a Tabela 2. Esses resultados podem evidenciar a influência da estrutura sintática de uma oração no seu reconhecimento, ou seja, o fato de a oração não ter o pronome inicial talvez explique a dificuldade dos informantes em discriminar as orações dos pares como iguais. Junte-se a isso, a questão de as orações terem tido suas frequências ampliadas, tornando o contorno melódico inverso ao padrão melódico das exclamativas.

A diferença entre os índices médios de recuperabilidade do padrão melódico da sentença nas diversas condições experimentais foi significativa $(\mathrm{p}=0,0351 \mathrm{~s})$.

Com base nos resultados apresentados da Tabela 2, verificamos que os pares de estímulos, com uma oração original mais uma oração com $\mathrm{F}_{0}$ reduzida, tiveram queda do índice de recuperabilidade conforme aumentava a taxa de manipulação. A recuperabilidade foi maior quando a exclamativa original foi comparada com a manipulada a 25 , um total de 70,8 de perceptibilidade. A 50 e 75, esse índice foi menor, 45,8 e 41,66, respectivamente.

A diferença entre os índices médios de recuperabilidade do padrão melódico da sentença nas diversas condições experimentais não foi significativa ( $\mathrm{p}=0,3539 \mathrm{~ns}$ ). 


\subsection{Análise perceptual das interrogativas: tarefa de identificação}

Tabela 3 - Índices médios de acerto obtidos na tarefa de identificação das Interrogativas com $\mathrm{F}_{0}$ da sílaba tônica do CT original, ampliada e reduzida a 25,50 e 75

\begin{tabular}{|c|c|c|c|c|c|c|c|c|c|c|}
\hline \multicolumn{11}{|c|}{ Condições experimentais } \\
\hline \multirow[t]{2}{*}{$\begin{array}{l}\text { Tipos de } \\
\text { sentença }\end{array}$} & \multicolumn{4}{|c|}{$\begin{array}{c}\text { Taxas de ampliação da } \mathrm{F}_{0} \mathrm{da} \\
\text { sílaba tônica do CT } \\
(\%)\end{array}$} & \multirow[t]{2}{*}{$\mathrm{p}$} & \multicolumn{4}{|c|}{$\begin{array}{c}\text { Taxas de redução da } \mathrm{F}_{0} \mathrm{da} \\
\text { sílaba tônica do CT } \\
(\%)\end{array}$} & \multirow[t]{2}{*}{$\mathrm{p}$} \\
\hline & Original & +25 & +50 & +75 & & Original & -25 & -50 & -75 & \\
\hline $\begin{array}{c}\text { Interrogativa } \\
\text { com } \\
\text { pronome }\end{array}$ & 100 & 5 & 50 & 37,5 & $\begin{array}{c}0,0492 \\
\mathrm{~s}^{(1)}\end{array}$ & 100 & 100 & 100 & 100 & $\begin{array}{c}1 \\
\mathrm{~ns}\end{array}$ \\
\hline $\begin{array}{c}\text { Interrogativa } \\
\text { sem } \\
\text { pronome }\end{array}$ & 66,67 & 50 & 58,32 & 41.67 & $\begin{array}{c}0,7590 \\
\text { ns (2) }\end{array}$ & 66,07 & 45,84 & 50 & 16.67 & $\begin{array}{c}0,3385 \\
\text { ns }\end{array}$ \\
\hline
\end{tabular}

Fonte: As autoras.

OBS: ${ }^{(1)} \mathrm{s}=$ significativo para $\mathrm{p} d " 0,05(\mathrm{alfa}=0,05)$

(2) $\mathrm{ns}=$ não significativo para $\mathrm{p}>0,05(\mathrm{alfa}=0,05)$

\section{Interrogativa com pronome ampliada e reduzida}

Os valores obtidos na tarefa de identificação de interrogativas parciais, com $\mathrm{F}_{0}$ ampliada, revelam que a mudança na curva melódica desse tipo de oração acarreta prejuízos para sua percepção. Observamos, de acordo com os resultados da Tabela 3, que o índice de acerto diminui conforme o aumento da taxa de manipulação. A 75, a perceptibilidade alcançou apenas 37,5\%.

A diferença entre os índices médios de acerto nas diversas condições experimentais foi significativa ( $p=0,0492 \mathrm{~s}$ ).

Com esses resultados, fica evidente que a ampliação da $\mathrm{F}_{0}$ compromete a inteligibilidade de uma interrogativa, mesmo com a presença do pronome, isso pode ser explicado pelo fato de o esperado para uma interrogativa parcial ser queda da $\mathrm{F}_{0}$ no final, e não subida.

As interrogativas parciais, com $\mathrm{F}_{0}$ reduzida, foram recuperadas em 100 pelos informantes em todas as taxas de manipulação. O desempenho dos informantes aqui pode ser explicado pela natureza do contorno melódico final de uma parcial que é descendente. Diferentemente do que ocorre com a 
ampliação que resulta em um contorno oposto, dificultando, assim, a percepção da frase.

Não houve, nesse caso, diferença entre os índices médios de acerto, o valor de p foi igual a 1 (cf. Tabela 3 ).

\section{Interrogativa sem pronome ampliada e reduzida}

Os informantes apresentaram dificuldade em recuperar uma interrogativa total com $\mathrm{F}_{0}$ ampliada, mesmo apresentando esse tipo de frase um contorno melódico ascendente. Como era esperado, conforme dados da Tabela 03, o menor índice de acerto foi da frase ampliada a 75, de 41,67.

Ainda de acordo com a Tabela 3, a diferença entre os índices médios de acerto nas diversas condições experimentais não foi significativa $(p=0,7590$ ns). Apesar de os índices de recuperabilidade nas diversas taxas de manipulação não terem apresentado diferença significativa, não se pode perder de vista que a perceptibilidade de uma interrogativa total não é uma tarefa 100 eficaz para o ouvinte, considerando que o índice médio de acerto da interrogativa total original foi de 66.67.

A interrogativa total com $\mathrm{F}_{0}$ reduzida, por sua vez, apresentou índices médios de acerto menores do que a da interrogativa com $\mathrm{F}_{0}$ ampliada. A ausência do pronome inicial somado à mudança no padrão melódico de uma interrogativa total, de ascendente para descendente, pode justificar a dificuldade dos informantes em perceber a modalidade do enunciado, de acordo com a Tabela 3 .

A diferença entre os índices médios de acerto nas diversas condições experimentais não foi significativa ( $p=0,3385 \mathrm{~ns}$, cf. Tabela 3). 


\subsection{Análise perceptual das interrogativas: tarefa de discriminação}

Tabela 4 - Índices médios de recuperabilidade obtidos na tarefa de discriminação das interrogativas com $\mathrm{F}_{0}$ da sílaba tônica do CT ampliada e reduzida a 25,50 e 75

\begin{tabular}{|c|c|c|c|c|c|c|c|c|}
\hline \multicolumn{9}{|c|}{ Condições experimentais } \\
\hline \multirow[t]{2}{*}{$\begin{array}{l}\text { Tipos de } \\
\text { sentença }\end{array}$} & \multicolumn{3}{|c|}{$\begin{array}{c}\text { Taxas de ampliação da } \\
\mathrm{F}_{0} \text { da sílaba tônica do } \\
\text { CT }(\%)\end{array}$} & \multirow[t]{2}{*}{$\mathrm{p}$} & \multicolumn{3}{|c|}{$\begin{array}{c}\text { Taxas de redução da } \mathrm{F}_{0} \\
\text { da sílaba tônica do } \mathrm{CT} \\
(\%)\end{array}$} & \multirow[t]{2}{*}{$\mathrm{p}$} \\
\hline & +25 & +50 & +75 & & -25 & -50 & -75 & \\
\hline $\begin{array}{c}\text { Interrogativa } \\
\text { com } \\
\text { pronome } \\
\end{array}$ & 41.67 & 8,32 & 4,17 & $0,0693 \mathrm{~ns}^{(1)}$ & 83,34 & 66,67 & 66,67 & $0,0505 \mathrm{~s}$ \\
\hline $\begin{array}{c}\text { Interrogativa } \\
\text { sem } \\
\text { pronome }\end{array}$ & 54,17 & 12,5 & 4,17 & $0,0156 \mathrm{~s}(2)$ & 79,17 & 83,32 & 54,17 & $0,08226 \mathrm{~ns}$ \\
\hline
\end{tabular}

Fonte: As autoras.

OBS: ${ }^{(1)} \mathrm{ns}=$ não significativo para $\mathrm{p}>0,05(\mathrm{alfa}=0,05)$.

${ }^{(2)} \mathrm{s}=$ significativo para $\mathrm{p} \mathrm{d}$ " $0,05(\mathrm{alfa}=0,05)$.

\section{Interrogativa com pronome ampliada e reduzida}

Os resultados obtidos na tarefa de discriminação com pares de estímulos formados por uma interrogativa parcial original mais uma interrogativa parcial com $\mathrm{F}_{0}$ ampliada, com base nos dados da tabela 04, apontam para o papel da $\mathrm{F}_{0}$ na percepção da melodia de uma frase. A manipulação feita no contorno final da interrogativa parcial trouxe confusão para os informantes. Quanto maior a taxa de ampliação, menor foi o índice de recuperabilidade. A 25 o índice médio de percepção foi de 41,67\%, de 8,32 a 50 e 4,17 quando ampliada a 75 .

A diferença entre os índices médios de recuperabilidade do padrão melódico da sentença nas diversas condições experimentais não foi significativa, conforme Tabela 4 ( $\mathrm{p}=0,0693 \mathrm{~ns}$ ).

A discriminação de uma interrogativa parcial com contorno final reduzido como sendo igual a uma original foi razoável. Os resultados mostram que a redução de uma interrogativa parcial não resultou em confusão com diferença significativa, com índice de recuperabilidade acima de 60 em todas as taxas de manipulação (cf. Tabela 4). Acreditamos que a presença do 
pronome e a configuração descendente da curva final de uma interrogativa expliquem esse valor. Assim como ocorreu na tarefa de identificação, em que as interrogativas parciais foram recuperadas em 100 quando tiveram o contorno final reduzido.

De acordo com a Tabela 04, a diferença entre os índices médios de recuperabilidade do padrão melódico da sentença nas diversas condições experimentais não foi significativa ( $\mathrm{p}=0,5005 \mathrm{~s})$.

\section{Interrogativa sem pronome ampliada e reduzida}

Os pares de estímulos formados por uma oração original interrogativa sem pronome mais uma oração com $\mathrm{F}_{0}$ ampliada obtiveram índices de recuperabilidade menores de acordo ao aumento de taxa de ampliação. Quanto maior o valor da taxa de manipulação, menos os informantes recuperavam a oração como igual à original que era comparada. Assim, a confusão foi menor quando a frase estava ampliada a 25, o índice médio de recuperabilidade foi de 54,17, quando ampliada a 50 foi de 12,5 e apenas 4,17 quando ampliada a 75, o que pode ser visto na Tabela 4.

A diferença entre os índices médios de recuperabilidade do padrão melódico da sentença nas diversas condições experimentais foi significativa ( $\mathrm{p}=0,0156 \mathrm{~s}$, cf. Tabela 4).

A percepção das interrogativas totais (sem pronome), comparadas à original, foi maior quando reduzida a taxas descendentes, apresentando índices de recuperabilidade acima de 50 em todas as taxas de redução, conforme Tabela 4. Esse resultado chama atenção tendo em vista o padrão melódico de uma interrogativa total, ou seja, acento nuclear ascendente. Esperávamos que, nas condições experimentais de elevação da $\mathrm{F}_{0}$, a percepção fosse maior, e não o contrário como ocorre.

A diferença entre os índices médios de recuperabilidade do padrão melódico da sentença nas diversas condições experimentais não foi significativa $(\mathrm{p}=0,0826 \mathrm{~ns})$. 


\subsection{Resultado do teste de regressão polinomial quadrática}

\subsubsection{Tarefa de Identificação}

\subsubsection{Exclamativas com pronome}

Se o valor de p obtido para as exclamativas com pronome for maior do que 0,05 significa dizer que o valor não é significativo, e assim, aceita-se $\mathrm{H}_{0}$ e rejeita-se $\mathrm{H}_{1}$, ou seja, o índice de acerto para a identificação desse tipo de enunciado não está associado a alterações da $\mathrm{F}_{0}$.

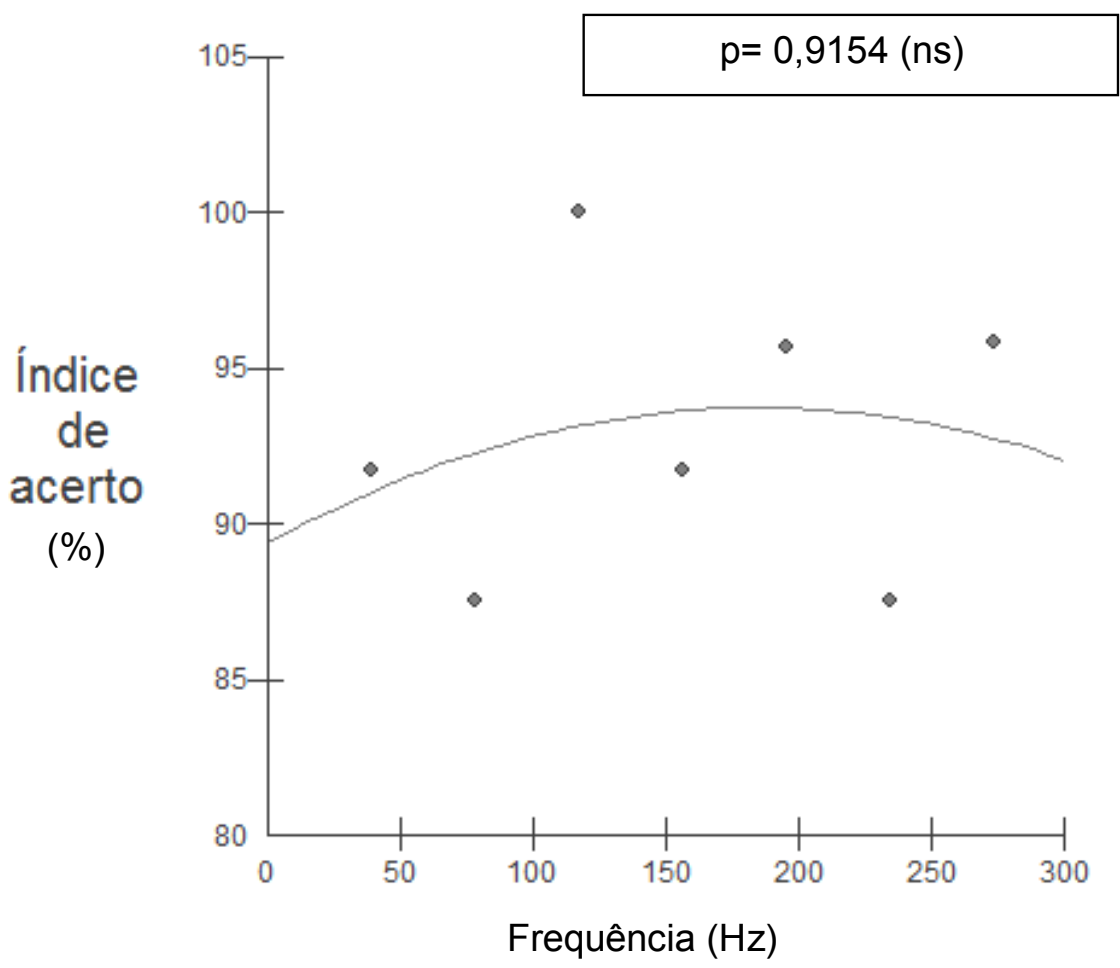

Fonte: As autoras.

Gráfico 1 - Teste de Regressão Polinomial Quadrática para o Índice de acerto das exclamativas com pronome 
De acordo com o Gráfico 1, o índice de acertos, que é superior a 90, ocorre independentemente do valor da $\mathrm{F}_{0}$ com que o enunciado foi apresentado ao informante. Dessa forma, podemos afirmar que o valor da $\mathrm{F}_{0}$ não influencia o índice de acerto das exclamativas com pronome $(\mathrm{p}=0,9164)$.

Em termos linguísticos, verifica-se que o índice de acerto das exclamativas com pronome não é influenciado pela variação de $\mathrm{F}_{0}$. A nossa hipótese é a de que a percepção desse tipo de sentença é desencadeada pela presença do pronome. Assim, para esse tipo de oração, o elemento desencadeador de sua percepção não está no sinal acústico, mas sim na estrutura da sentença. Os dados encontrados para as sentenças sem pronome endossam essa hipótese.

\subsubsection{Exclamativas sem pronome}

Diferentemente do que foi encontrado para a exclamativa com pronome, para as exclamativas sem pronome, o valor de $\mathrm{p}$ é significativo, menor que $0,05(\mathrm{p}=0,0057)$. Dessa forma, aceita-se $\mathrm{H}_{1}$ e rejeita-se $\mathrm{H}_{0}$, ou seja, a variável dependente, o índice de acerto, sofre alterações em função da variável independente, $\mathrm{F}_{0}$.

Sendo $\mathrm{p}$ significativo, é preciso avaliar o valor de $\mathrm{R}^{2}$ que é igual a 0,8368 , o que significa que a $\mathrm{F}_{0}$ explica quase 84 do índice de acerto, conforme Gráfico 2.

Observa-se, no Gráfico 2, que quanto mais aumenta o valor da frequência, maior é o índice de acerto da percepção da exclamativa sem pronome. Essas exclamativas são mais bem percebidas nas faixas de frequências de $150 \mathrm{~Hz}$ e $300 \mathrm{~Hz}$. 


$$
\begin{aligned}
& \mathrm{p}=0,0057 \\
& \mathrm{R}^{2} \text { (ajustado) }=0,8368
\end{aligned}
$$

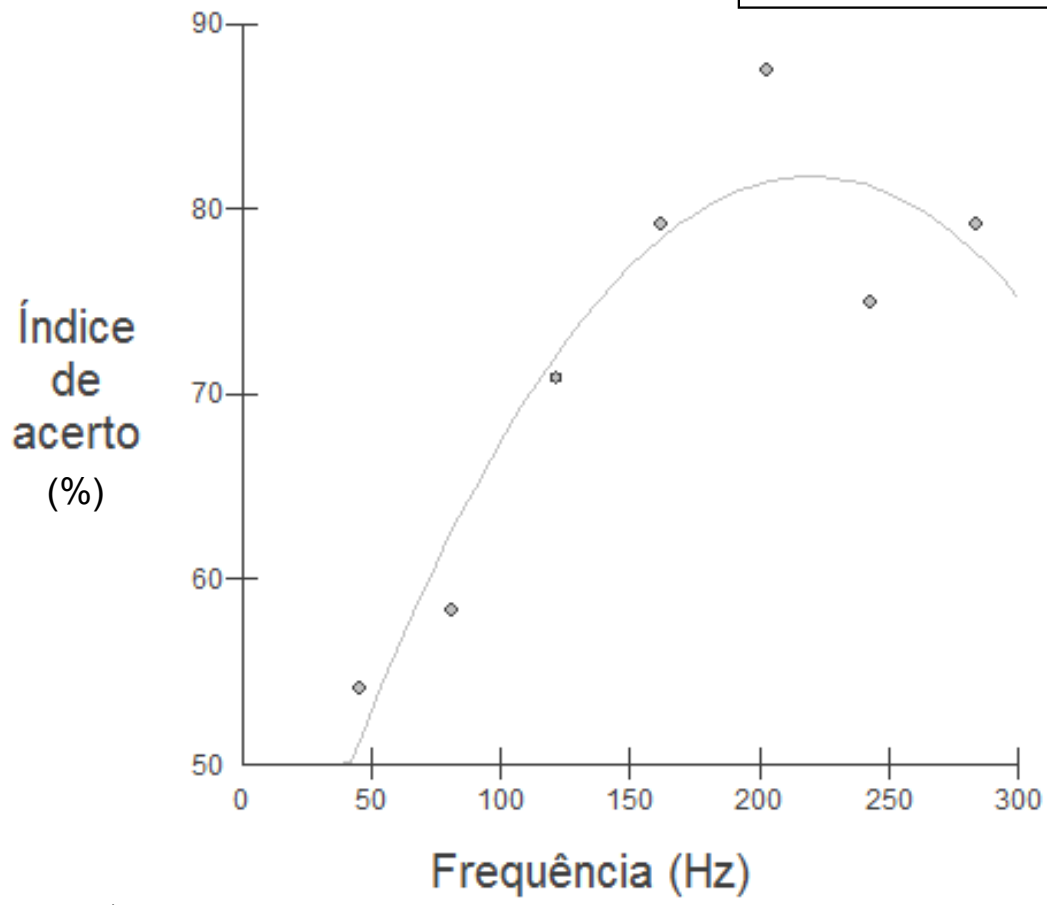

Fonte: As autoras.

Gráfico 2 - Teste de Regressão Polinomial Quadrática para o Índice de acerto das exclamativas sem pronome

\subsubsection{Interrogativas com pronome}

Se por um lado a presença do pronome desencadeia a percepção da exclamativa com pronome, independentemente do valor da frequência, por outro a interrogativa com essa mesma estrutura frasal possui seu índice de acerto associado ao valor da $\mathrm{F}_{0}$, conforme podemos observar no Gráfico 3.

$\mathrm{O}$ valor de p para as interrogativas com pronome é igual a 0,011 , ou seja, menor do que 0,05 , assim, aceita-se $\mathrm{H}_{1}$ e rejeita-se $\mathrm{H}_{0}$. $\mathrm{O}$ índice de acerto, nesse caso, é dependente da $\mathrm{F}_{0}$. De acordo com o valor de $\mathrm{R}^{2}$, igual a 0,9470 , 
podemos afirmar que a $\mathrm{F}_{0}$ explica quase $95 \mathrm{da}$ perceptibilidade de uma interrogativa com pronome. Além disso, com base nos dados desse gráfico, avaliamos que as frequências compreendidas entre $45 \mathrm{~Hz}$ e $150 \mathrm{~Hz}$ são as que acarretam maiores índices de acerto, acima de 90.

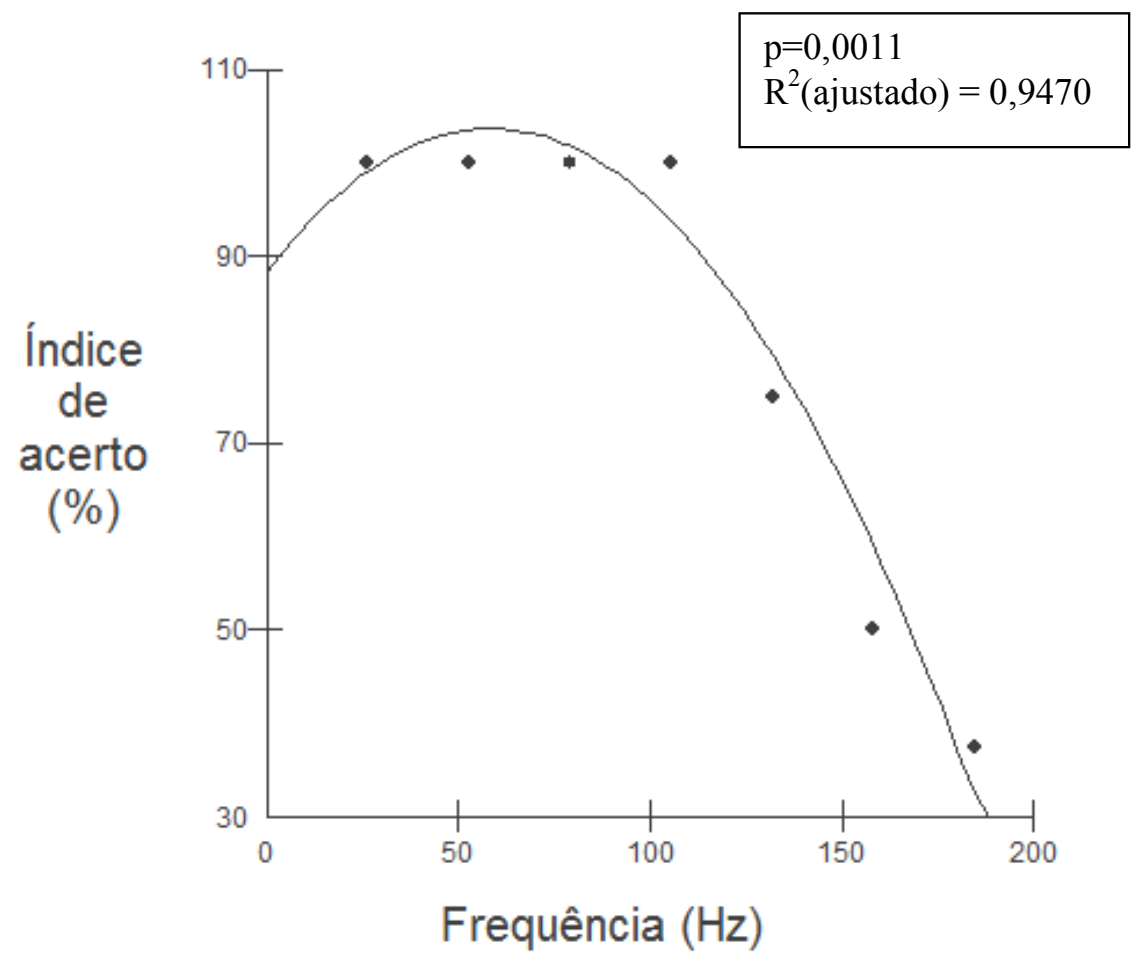

Fonte: As autoras.

Gráfico 3 - Teste de Regressão Polinomial Quadrática para Índice de acerto de percepção de interrogativas com pronome

\subsubsection{Interrogativas sem pronome}

Para as interrogativas sem pronome, o valor de p é igual a 0,0296. Sendo p menor do que 0,5 , aceita-se $\mathrm{H}_{1}$ e rejeita-se $\mathrm{H}_{0}$, ou seja, o índice de acerto sofre alterações com a $\mathrm{F}_{0}$ (cf. Gráfico 4). 
Como o valor de $\mathrm{p}$ foi significativo, tem-se $\mathrm{R}^{2}$ que é igual a 0,6606, o que indica que a $\mathrm{F}_{0}$ explica quase 67 do índice de acerto.

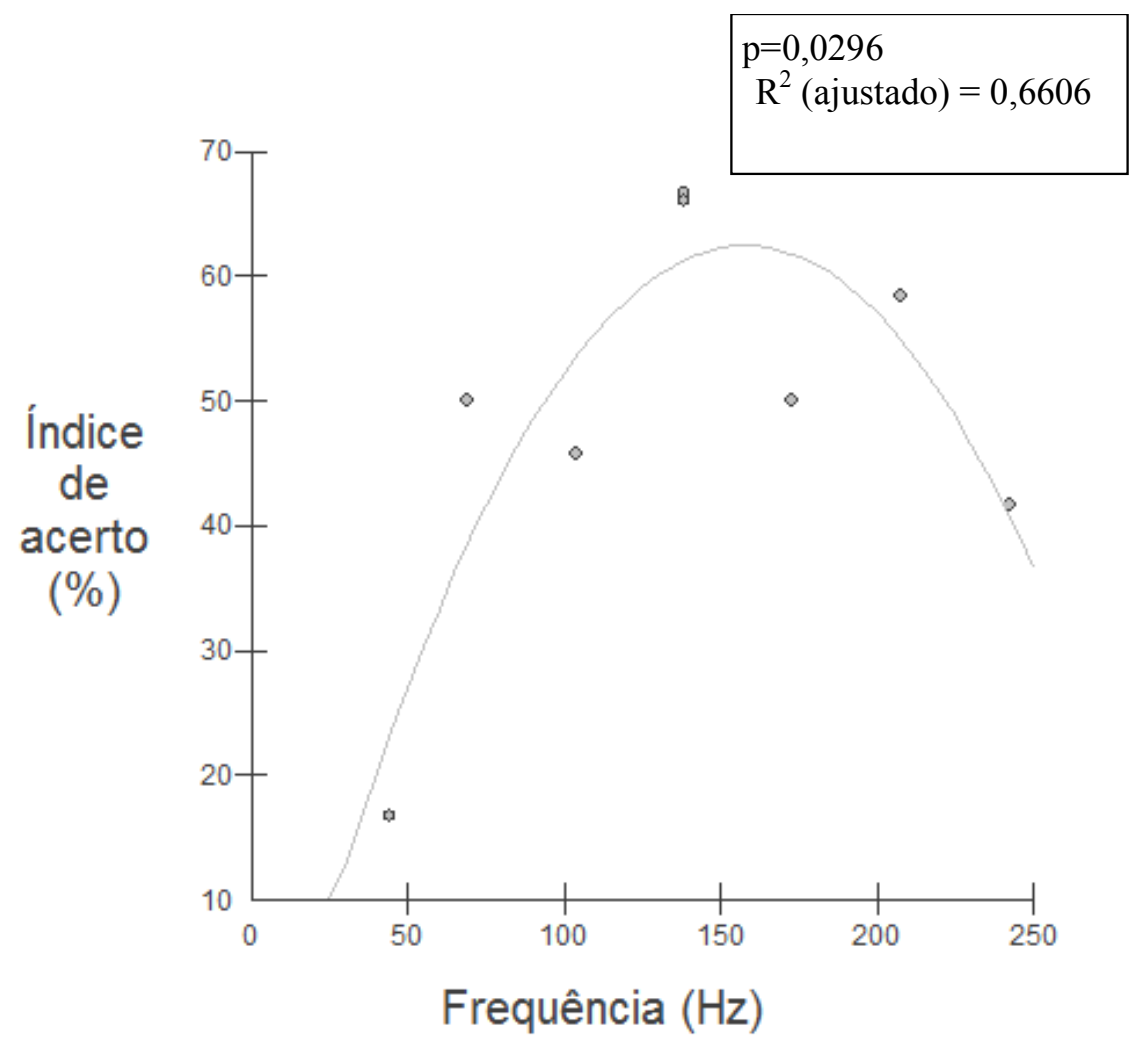

Fonte: As autoras.

Gráfico 4 - Teste de Regressão Polinomial Quadrática para Índice de acerto de percepção de interrogativas sem pronome

Ainda de acordo com o Gráfico 4, essa interrogativa é mais percebida, em torno de 70 , na faixa de frequência de $145 \mathrm{~Hz}$. 


\subsubsection{Tarefa de Discriminação}

\subsubsection{Exclamativas com pronome}

Com base no Gráfico 5, verificamos que para a exclamativa com pronome, temos o valor de $\mathrm{p}=0,5166$. Com isso aceita-se $\mathrm{H}_{0}$ e rejeita-se $\mathrm{H}_{1}$. $\mathrm{O}$ índice de recuperabilidade desse tipo de exclamativa não é dependente do valor a $\mathrm{F}_{0}$, ou seja, os diferentes valores da $\mathrm{F}_{0}$ não afetam a recuperabilidade desse tipo de exclamativa.

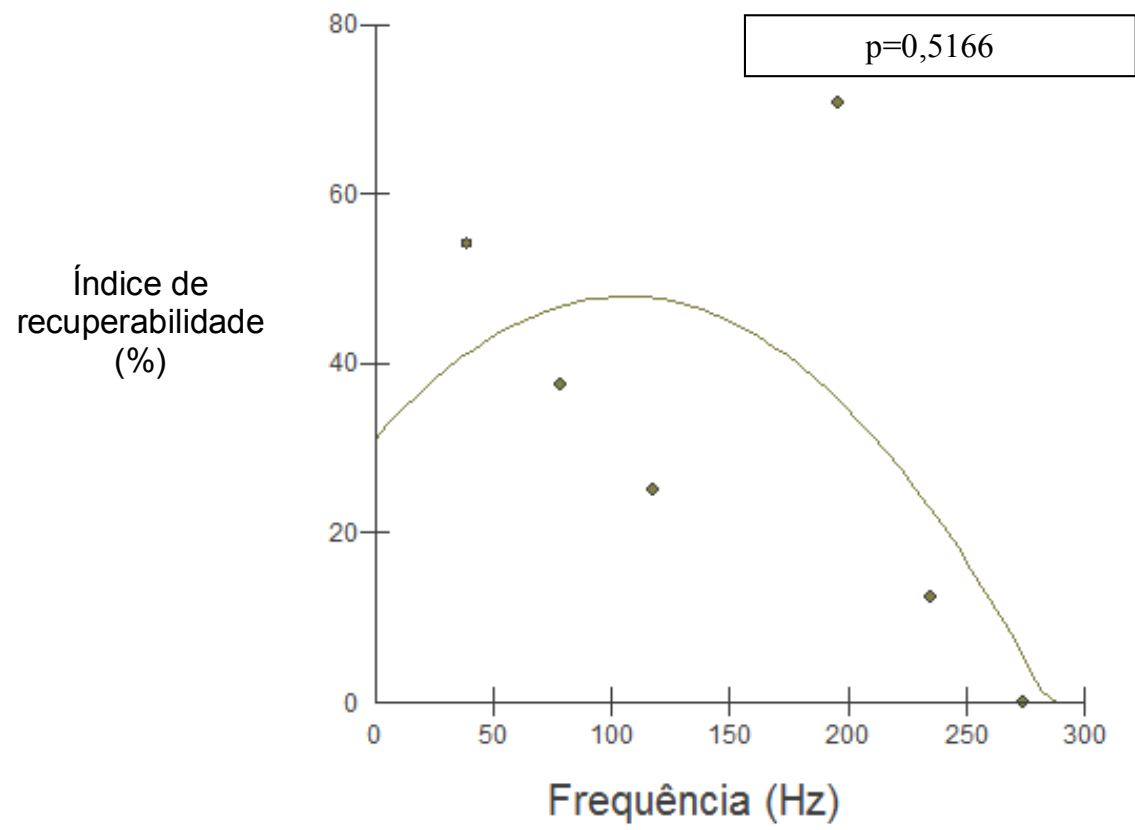

Fonte: As autoras.

Gráfico 5 - Teste de regressão quadrática para índice de recuperabilidade de exclamativas com pronome 


\subsubsection{Exclamativas sem pronome}

O valor de pé igual a 0,049, isto é, menor que 0,05, consequentemente, aceita-se $\mathrm{H}_{1}$ e rejeita-se $\mathrm{H}_{0}$, o que mostra que o índice de recuperabilidade sofre alterações em função da $F_{0}$ (cf. Gráfico 6).

O coeficiente de determinação, valor que determina o quanto a variável dependente é explicada pela variável preditora, é igual a 0,7639, o que significa que a $\mathrm{F}_{0}$ explica quase 77 do índice de recuperabilidade de uma exclamativa sem pronome.

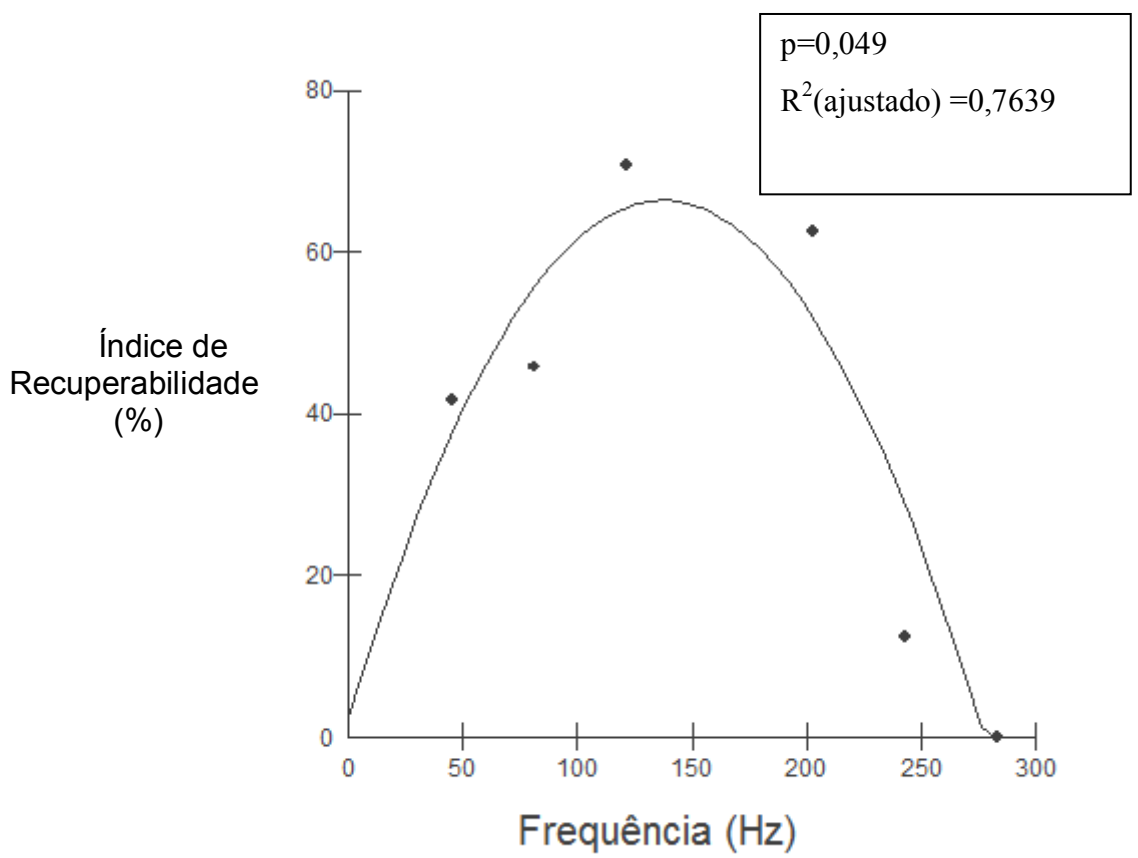

Fonte: As autoras.

Gráfico 6 - Teste de regressão quadrática para índice de recuperabilidade de exclamativas sem pronome

As manipulações realizadas com $\mathrm{F}_{0}$ que estão entre $145 \mathrm{~Hz}$ e $225 \mathrm{~Hz}$, nesses dados experimentais, levam o sujeito a recuperar como exclamativas os enunciados manipulados. 


\subsubsection{Interrogativas com pronome}

Para as interrogativas com pronome, o valor de $\mathrm{p}=0,05$, sendo assim, aceita-se $\mathrm{H}_{1}$ e rejeita-se $\mathrm{H}_{0}$, o que aponta que o índice de recuperabilidade desse tipo de enunciado sofre alterações com a manipulação da $F_{0}$ (cf. Gráfico 7).

Neste caso, tem-se $R^{2}$ igual a 0,7217 , ou melhor, a $F_{0}$ explica quase 73 do índice de recuperabilidade.

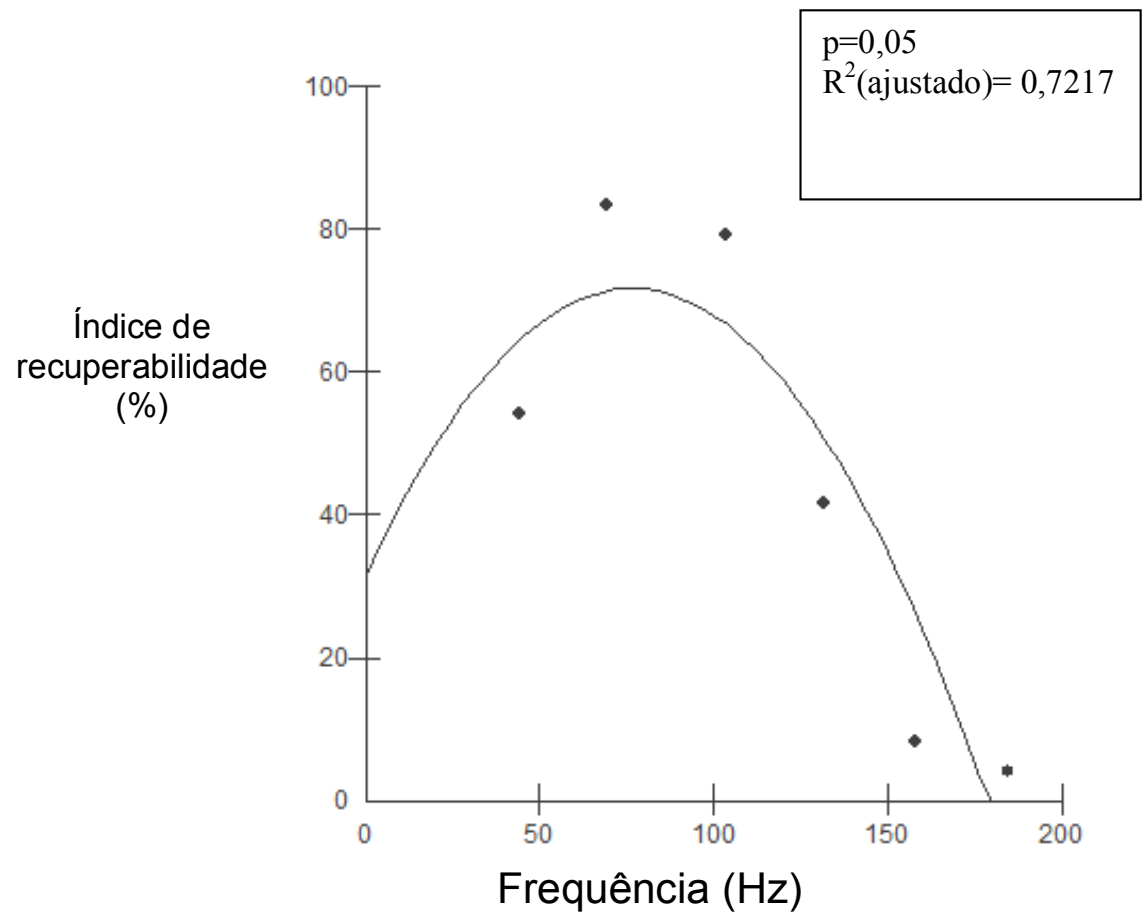

Fonte: As autoras.

Gráfico 7 - Teste de regressão quadrática para índice de recuperabilidade de interrogativas com pronome

Os maiores índices de recuperabilidade das interrogativas com pronome ocorrem nas faixas de frequência entre $55 \mathrm{~Hz}$ a $145 \mathrm{~Hz}$. 


\subsubsection{Interrogativas sem pronome}

Avaliando os dados dispostos no Gráfico 8, verificamos que o valor de $\mathrm{p}$ é significativo $(\mathrm{p}=0,0353)$, isto é, menor que 0,05. Dessa forma, aceita-se $\mathrm{H}_{1}$ e rejeita-se $\mathrm{H}_{0}$. Sendo assim, o índice de recuperabilidade é afetado com a variação da $\mathrm{F}_{0}$.

O coeficiente de determinação é igual $\mathrm{R}^{2}=0,7217$, o que aponta que a $\mathrm{F}_{0}$ explica quase 73 do índice de recuperabilidade.

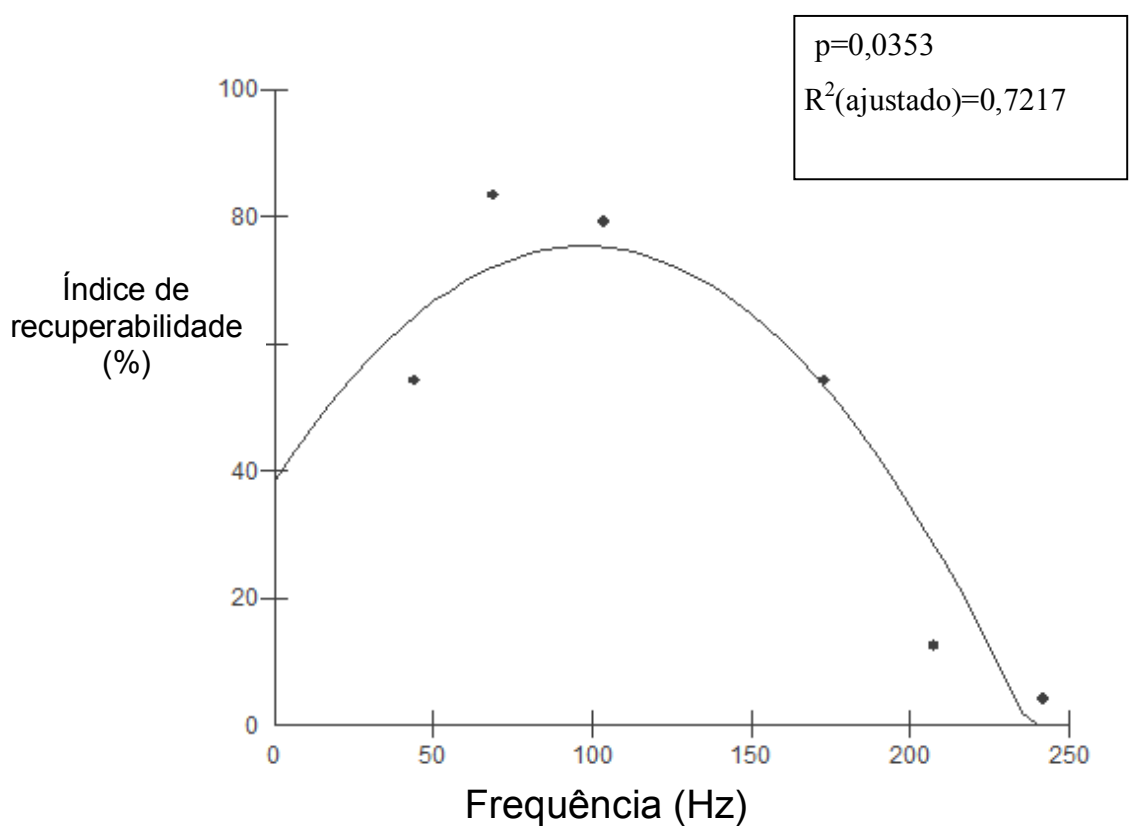

Fonte: As autoras.

Gráfico 8 - Teste de regressão quadrática para índice de recuperabilidade de interrogativas sem pronome

Os valores de $\mathrm{F}_{0}$ que ocorrem entre $55 \mathrm{~Hz}$ e $110 \mathrm{~Hz}$ são que promovem maior índice de recuperabilidade das interrogativas sem pronome. $\mathrm{F}_{0}$ maiores, superiores a $200 \mathrm{~Hz}$, levam o informante a não reconhecer no sinal acústico uma interrogativa. 


\subsubsection{Reflexões acerca do teste de Regressão Polinomial Quadrática}

Nos resultados obtidos na tarefa de identificação, o teste de regressão comprova que a variação da $\mathrm{F}_{0}$ exerce um papel essencial na identificação da modalidade de uma frase. Com exceção da exclamativa com pronome, que teve alto índice de acerto em sua identificação, independentemente do valor da frequência, os demais casos mostram haver uma dependência entre a identificação do tipo melódico e a $\mathrm{F}_{0}$. Ou seja, a $\mathrm{F}_{0}$ consegue explicar satisfatoriamente os resultados alcançados nos testes de percepção.

Nossa explicação para o resultado obtido para a exclamativa com pronome é a de que a presença da palavra exclamativa, nesse caso, o como, já carrega em si a modalidade exclamativa. Para a interrogativa com pronome, contudo, não se aplica essa mesma explicação haja vista que sua perceptibilidade é altamente explicada pelos valores da $\mathrm{F}_{0}(95 \%)$.

A dependência entre perceptibilidade e valores da $\mathrm{F}_{0}$ é também atestada nas sentenças sem pronome, tanto exclamativa como interrogativa. Os tipos melódicos aqui avaliados foram mais percebidos em diferentes faixas de $\mathrm{F}_{0}$.

$\mathrm{Na}$ tarefa de discriminação, o índice de recuperabilidade das exclamativas com pronome, da mesma forma que ocorreu no teste de identificação, não foi afetado pela variável independente. Nessa tarefa, contudo, o pronome do início não foi suficiente para que o sujeito de nossa pesquisa recuperasse como exclamativa os estímulos com a $\mathrm{F}_{0}$ manipulada, tanto para valores ascendentes como para valores descendentes. No entanto, o índice de recuperabilidade também não é explicado pelo valor da F0, como indica o valor de $\mathrm{p}$ maior do que 0,05 . Nos demais casos, exclamativas sem pronome e interrogativas com e sem pronome, tiveram os índices de recuperabilidade afetados pela variação da $\mathrm{F}_{0}$.

Esses resultados evidenciam que a percepção de exclamativas e interrogativas pode ser otimizada em faixas de frequências específicas. Em outras palavras, certas faixas de $\mathrm{F}_{0}$ favorecem a percepção de exclamativas e interrogativas enquanto outras comprometem esse processo. Apropriando-se dos princípios básicos da Teoria Quântica, podemos dizer que essas faixas de frequências que favorecem a percepção desses tipos melódicos constituem regiões quânticas que definem padrões melódicos que contrastam exclamativas e interrogativas.

De acordo com os resultados obtidos, as exclamativas sem pronome possuem maior perceptibilidade nas frequências em torno de $150 \mathrm{~Hz}$ e $300 \mathrm{~Hz}$, 
ao passo que as interrogativas são mais percebidas em faixas menores em torno de $45 \mathrm{~Hz}$ e $150 \mathrm{~Hz}$.

O contorno melódico que caracteriza um e outro tipo melódico pode ser mais bem percebido como tal quando realizado com o valor da $F_{0}$ nas faixas acima discriminadas. Talvez aqui esteja uma explicação possível para o fato de muitas vezes, em uma situação comunicativa, o ouvinte questionar diante de um enunciado interrogativo: "isso é uma pergunta?". É possível que a percepção de que aquele enunciado seja uma interrogativa não ocorra satisfatoriamente justamente pelo fato de ele não ter sido realizado dentro das regiões quânticas esperadas.

Nossa hipótese é a de que as exclamativas são mais bem percebidas com frequências maiores que a das interrogativas porque o contorno descendente desse tipo melódico fica mais evidente nessas frequências maiores e as interrogativas encontram maior evidência de seu contorno, tanto ascendente, quanto descendente, nas frequências menores.

Diante desses arrazoados, emerge uma pergunta: o que torna certas faixas de frequências favoráveis à percepção de uma exclamativa e não de uma interrogativa e vice-versa?

Para nós, à semelhança do que ocorre na percepção de vogais e consoantes, de acordo com Stevens (1980), o sistema auditivo responde a sons com diferentes propriedades acústicas de diferentes formas. Essas respostas especiais exercem um papel importante na seleção e classificação do inventário sonoro das línguas. No nosso caso especificamente, a seleção das faixas de frequências garante a oposição existente na língua entre exclamativas e interrogativas.

Assim, uma manipulação da $\mathrm{F}_{0}$ que fosse no mesmo sentido do contorno melódico da sentença, ampliação para o contorno ascendente ou redução para o contorno descendente - não seria condição sine qua non para uma boa performance na percepção desses tipos oracionais. Se a manipulação resultasse em uma sentença com sinal acústico com frequências localizadas fora das regiões quânticas (como propostas acima), a percepção de uma exclamativa ou de uma interrogativa estaria comprometida.

Diante disso, defendemos que para que haja uma percepção a contento de exclamativas e interrogativas, o sinal acústico deva conter frequências com certos valores específicos, os quais serão processados, por contraste, pelo sistema auditivo como uma exclamativa ou como uma interrogativa. 


\section{Conclusões}

Dentro dos limites metodológicos e dos procedimentos analíticos aqui adotados, os resultados obtidos nesta pesquisa permitiram endossar o papel da $\mathrm{F}_{0}$ no processo de percepção de frases exclamativas e interrogativas. $\mathrm{O}$ que permite responder a pergunta proposta no início do trabalho, ou seja, o quanto de variação da $F_{0}$ é necessário para se garantir a perceptibilidade de um determinado tipo de frase?

A partir dos resultados alcançados no teste de percepção, atestamos que a $\mathrm{F}_{0}$ tem um papel relevante no desenvolvimento da percepção dos contornos entoacionais. A mudança feita na curva entoacional acarretou, em maior ou menor grau, dificuldade na hora de identificar uma frase.

Constatamos, também, que a presença do pronome no início da sentença, também desempenha um papel relevante no processo de interpretação de uma frase. No teste de identificação, os informantes não tiveram dificuldade em identificar o tipo de frase quando essa era composta com pronome. No entanto, como prevíamos, o maior índice de erro ocorreu com a interrogativa parcial $\mathrm{F}_{0}$ ampliada, uma vez que o contorno melódico se tornou oposto ao seu padrão. $\mathrm{O}$ mesmo não ocorreu com a exclamativa com pronome, nessa mesma condição experimental, o que reforça, portanto, a importância do pronome inicial para a identificação da modalidade.

A tarefa de identificação, para as sentenças sem pronome, também aponta para a influência da $\mathrm{F}_{0}$ no reconhecimento do tipo de frase. Como era esperado, o menor desempenho dos informantes foi na identificação das frases ampliadas a 75, exceto nas exclamativas ampliadas nas quais o menor índice de reconhecimento ocorreu a 50 . Na tarefa de discriminação, o mesmo foi observado. Em todos os casos a maior dificuldade em discriminar foi ampliada a 75, ficando em 0 a discriminação das exclamativas com $\mathrm{F}_{0}$ ampliada.

$\mathrm{Na}$ tentativa de confirmar esses resultados, realizamos um teste de regressão linear polinomial quadrática que visou determinar o nível de dependência entre a frequência fundamental e os índices de acerto e recuperabilidade. As análises foram feitas à luz da Teoria Quântica da Percepção da fala. Os resultados mostraram que: a variação da $\mathrm{F}_{0}$ tem participação essencial na identificação do contorno melódico de uma frase. Com exceção das exclamativas com pronome, os demais casos sofreram influência significativa da $\mathrm{F}_{0}$, tanto na hora de identificar a modalidade como na hora de discriminar. Assim, somos capazes de afirmar que a percepção de exclamativas e 
interrogativas ocorre em função de regiões quânticas do sinal acústico. Quando o sinal acústico não apresenta região quântica específica para o contraste de exclamativa e interrogativa temos o processo de percepção desses tipos de orações comprometido.

Finalmente, conforme exposto em nossa introdução, os recursos suprassegmentais desempenham uma função muito importante no processo de compreensão da fala. A partir deles, é possível interpretar as intenções comunicativas, essenciais para o processo de comunicação. Sendo assim, este estudo pode contribuir com os estudos prosódicos tendo em vista a sua importância para o sucesso da comunicação. Sendo um estudo original, no que tange ao tema tratado, certamente, não esgotamos o assunto, e nem pretendíamos. Esperamos, entretanto, que as reflexões feitas aqui sirvam de norte para outras futuras pesquisas. E acreditamos que novas estratégias metodológicas devam ser pensadas com o objetivo de responder o que ficou sem resposta e de alcançar novos resultados que contribuam com a pesquisa prosódica.

Sugerimos como pesquisas futuras avaliar o papel da intensidade e duração de maneira a ser possível quantificar o papel de cada um desses parâmetros. Sugerimos também que se avalie o papel desses parâmetros sobre as sílabas do CPT.

\section{Referências}

AYRES M. et al. BioEstat 5.0 - aplicações estatísticas nas áreas das Ciências Biológicas e Médicas: Sociedade Civil Mamirauá, Belém. Brasília: CNPq, 2007.

BOERSMA, P.; WEENINK, D. Praat: doing phonetics by computer. Version 5.1.43. 2006. Disponível em: <http://goo.gl/gm7bx>. [Programa de computador].

BORDEN, G. J.; HARRIS, K. S.; LAWRENCE, J. R. Speech Science Primer. physiology, acoustics, and perception of speech. 3. ed. Baltimore: Williams \& Wilkins, 1994.

CAGLIARI, L. C. Elementos de fonética do Português Brasileiro. 1982. Tese (Livre Docência) - Universidade Estadual de Campinas, Campinas. 
CAGLARI, L. C. Elementos de fonética do Português Brasileiro. São Paulo: Paulistana, 2007.

FRY, D. B. Acoustic phonetics: a course of basic readings. Cambridge: Cambridge University Press, 1976.

HALLIDAY, M. A. K. A course in spoken English: intonation. London: Oxford University Press, 1970.

JOHNSON, K. Acoustic and auditory phonetics. 2. ed. Oxford: Blackwell, 1997.

LEHISTE, I. Suprassegmentals. Cambridge: MIT Press, 1970.

LIBERMAN, A. et al. Perception of the speech code. Psychological Review, v. 74, p. 431-461, 1967.

MATEUS, M. H. et al. Gramática da língua portuguesa. 2. ed. Lisboa: Caminho, 1994.

MORAES, J. A. The pitch accents in Brazilian Portuguese: analysis by synthesis. In: CONFERENCE ON SPEECH PROSODY, 4., 2008, Campinas. Proceedings of the Speech Prosody. Campinas: Unicamp, 2008. p. 389-397.

OLIVEIRA, J. S. N. Análise acústico-perceptual das frases exclamativas e interrogativas realizadas por falantes de Vitória da Conquista/BA. 2014. Dissertação (Mestrado em Linguística) - Universidade do Sudoeste da Bahia, Vitória da Conquista.

PACHECO, V. O efeito dos estímulos auditivo e visual na percepcão dos marcadores prosódicos lexicais e gráficos usados na escrita do Português Brasileiro. 2006. Tese (Doutorado em Linguística) - Universidade Estadual de Campinas, Campinas.

SCARPA, E. M. Apresentação. In: SCARPA E. M. (Org.). Estudos de prosódia. Campinas: Editora da Unicamp, 1999. p. 7-17.

STEVENS, K. N. The quantal nature of speech: evidence from articulatory-acoustic data. In: DAVID, E. E.; DENES, P. B. (Orgs.). Human communication: a unified view. Nova York: McGraw Hill, 1972. p. 51-56. 
STEVENS, K. N. Acoustic correlates of some phonetics categories. The Journal of the Acoustical Society of America, v. 68, n. 3, p. 836-842, Mar. 1980. STEVENS, K. N. On the quantal nature of speech. Journal of Phonetics, v. 17, p. 3-45, 1989.

SUMBY, W. H.; POLLACK, I. Visual contribution to speech intelligibility in noise. The Journal of the Acoustical Society of America, v. 26, n. 3, p. 212-215, Mar. 1954.

't HART, J.; COLLIER, R.; COHEN, A. A perceptual study of intonation. Cambrigde: Cambrigde University Press, 1990.

Recebido em: 31/03/2014 Aceito: $21 / 08 / 2014$ 